\title{
Trifolium repens L. genetic changes after UV-B radiation on the base of retrotransposon movement
}

\author{
Sandra Dombrovska, Dace Grauda*, Andra Miḳelsone \\ Institute of Biology, University of Latvia, Jelgavas Street 1, Riga, Latvia, LV-1004 \\ *Corresponding author: dace.grauda@lu.lv
}

\begin{abstract}
The white clover (Trifolium repens L.) has a wide distribution range of habitat - from the Arctic to the subtropics, as well as up to $6000 \mathrm{~m}$ high alpine regions. It is found in various areas - in the wild, in agricultural areas, and the urban environment. Retrotransposons are mobile genetic elements that can move through the genome using the "copy-paste" principle are activated when a plant is affected by a stressor. The ability to respond to environmental changes makes retrotransposons very successful functional markers for a stress study. A universal retrotransposon-based method iPBS (inter primer binding sites) which was developed by Kalendar et al. (2010) was used for the study of UV irradiation influence. It can be observed that after the treatment with UV-B radiation, the movement of retrotransposons is activated, which suggests that in this way protection against UV-B radiation is provided. It can be observed that the insertion of retrotransposons after irradiation with UV-B radiation within the same genotype takes place in the approximately same location in all the examined groups - after UV-B irradiation 15, 30, and 45 minutes.
\end{abstract}

Keywords: Trifolium repens, UV-B radiation, retrotransposons

\section{Introduction}

White (Dutch) clover Trifolium repens $\mathrm{L}$. is a cross-pollinated perennial herb that belongs to legume family (Leguminosae Juss.), typicum variety, both diploids $(2 \mathrm{n}=2 \mathrm{x}=16)$ and tetraploids plants $(2 \mathrm{n}=4 \mathrm{x}=32)$ are known (Voysey et al., 1994; Zhang et al., 2007; Jansone, 2008). T. repens grow worldwide and is one of the plant species cultivated in temperate climate zone in meadows, yards, gardens, along roads and streets, etc. (Roze, 2003; Roze, 2007; Ravagnani et al., 2012). It is also one of the components of grasslands. Since white clover is widespread in urban areas, including with various environmental pollution levels, it is the perfect plant species for adaptation studies. 
UV radiation ( $280-400 \mathrm{~nm}$ ), which reaches the Earth's surface, effectively regulates various physiological processes and metabolic pathways required for plant development. High absorption of UV radiation, especially UV-B $(280-316 \mathrm{~nm})$, can damage biological systems by degrading cellular DNA, reducing plant photosynthesis, chloroplast tilyloid integrity, and efficient biomass production. As a result of increased UV-B radiation intensity, reactive oxygen species as well as oxidative stress increase in plants. UV tolerance can vary significantly between species and varieties - some cultures may already be highly sensitive to current natural levels of UV-B radiation. Due to the great diversity of physiological and biochemical properties between species and varieties, as well as the increased plasticity and adaptive capacity observed under different growing conditions, it is worth studying the effects of UV-B radiation on populations from different environmental conditions, as climate change is predicted to have adverse effects on plant diversity (Caradus, 1994; Oliveira et al., 2019; Romero-Román et al., 2021).

This study is aimed to study the influence of UV irradiation on T. repens. A universal retrotransposon-based method iPBS (inter primer binding sites) which was developed by Kalendar et al. (2010) allows revealing a high level of genetic diversity and cost and labor are effective is cohoused for the study of UV irradiation influence. Retrotransposons are mobile genetic elements that can move through the genome using the "copy-paste" principle, thus multiplying themselves. Many studies show that retrotransposons are activated when a plant is affected by a stressor. The ability to respond to environmental changes makes retrotransposons successful functional markers responsible for adapting to changing environmental conditions (Bui and Grandbastien, 2012; Casacuberta and Gonzales, 2013).

\section{Material and methods}

\section{Plant material}

Four genotypes seeds of T. repens were used for the UV-B radiation experiment: Latvia origin variety "Daile", as well as genotypes from Gene Bank of the Slovak Republic from three different Tatra Mountains locations - Makov-Lovasovci (genotype 7), Oscadnica-Haladeji (genotype 9) and Oravsky Biely Potok (genotype 11). The experimental plants were grown in vitro under sterile conditions. The seeds were sterilized in three stages: 1) 10 minutes in soapy water, then rinsed with deionized water (at least 3 times); 2) 30 minutes in $0.7 \% \mathrm{KMnO} 4$ solution, then rinsed with deionized water; 3) 20 minutes in commercialized bleach solution ACE with a drop of Tween 80 , then rinsed with deionized autoclaved water in a laminar flow box. Sterile seeds were plated on Petri dishes on 6\% agar (pH 5.8) and placed in a $24{ }^{\circ} \mathrm{C}$ light thermostat with a photoperiod of $16 / 8$ hours day/night. After 21 days, the germinated plants were transplanted into cultivation boxes $(11 \times 9.5 \times 8 \mathrm{~cm})$ on 
L2 medium (Taylor and Quesenberry, 1996) and continued to grow in a thermostat under the same conditions.

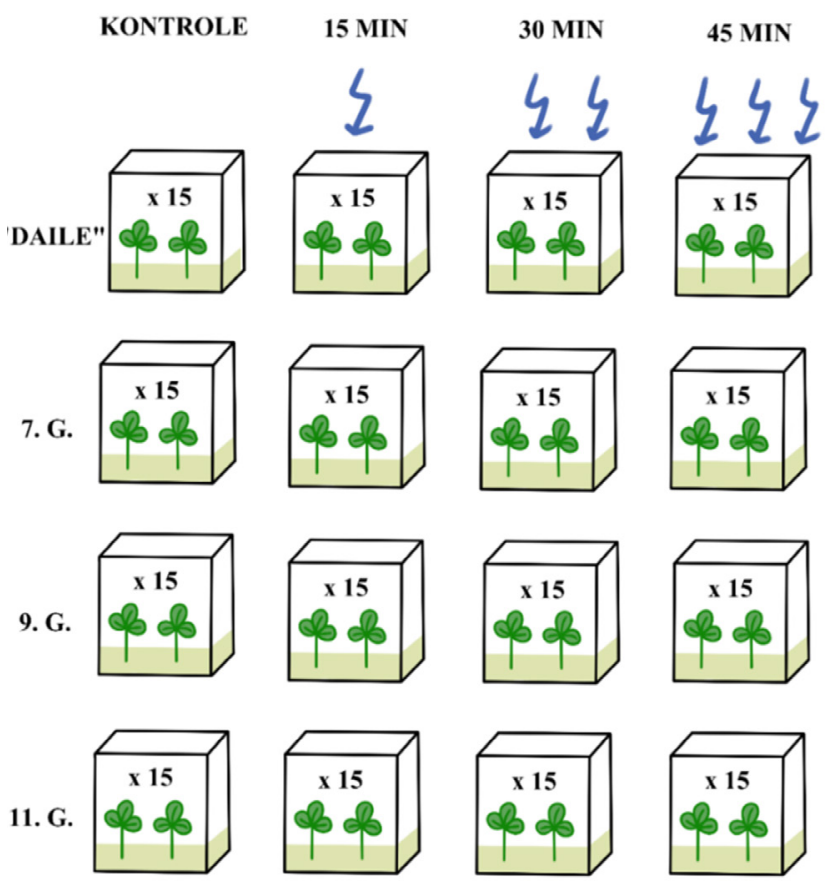

Figure 1. UV-B radiation experiment design ("Daile" - Latvian commercial variety "Daile"; 7. G. $-7^{\text {th }}$ genotype (Makov-Lovasovci); 9. G. $-9^{\text {th }}$ genotype (Oscadnica-Haladeji); 11 . G. $11^{\text {th }}$ genotype (Oravsky Biely Potok); KONTROLE - control group; 15 MIN - radiation with UV-B 15 minutes; 30 MIN - radiation with UV-B 30 minutes; 45 MIN - radiation with UV-B 45 minutes).

\section{UV-B irradiation experiment}

T. repens explants (leaves) taken from plants with at least four mature leaves were used for the UV-B irradiation experiment. 15 explants were planted on L2 medium in each in vitro cultivation box. Four experimental groups were set up: control and three with UV-B irradiation for 15, 30, and 45 minutes (Figure 1). The experiment was performed for seven days, irradiating at the same time each day.

\section{Molecular analysis}

After treatment of T. repens explants with UV-B radiation, DNA was isolated from all samples. DNA was isolated using CTAB DNA extraction protocol (Doyle and Doyle, 1987). 
PCR was performed on two primers, iPBS 2076 (5'-GCTCCGATGCCA-3') and iPBS 2079 (5'-AGGTGGCGCCA-3'). PCR for iPBS analysis was performed following Kalendar et al. (2010) protocol. PCR was performed in $0.2 \mathrm{~mL}$ tubes, the final volume of the reaction mixture was $25 \mu \mathrm{l}$, containing 1x DreamTaq PCR buffer, $1 \mathrm{mM}$ primer, $0.2 \mathrm{mM}$ each dNTP, $1.25 \mathrm{U}$ DreamTaq DNA polymerase, and 20-25 ng DNA. DNA amplification was performed in a GeneAmp PCRSystem 9700. PCR program included the following steps: initial denaturation at $95^{\circ} \mathrm{C}$ for 3 min, 30 cycles $\left(95^{\circ} \mathrm{C}\right.$ for $20 \mathrm{~s}, 50^{\circ} \mathrm{C}$ for $60 \mathrm{~s}, 68^{\circ} \mathrm{C}$ for $60 \mathrm{~s}$ ), and the final synthesis for $10 \mathrm{~min}$ at $72^{\circ} \mathrm{C}$.

PCR products were visualized using electrophoresis at $107 \mathrm{~V}$ for 7 hours on $1.7 \%$ agarose gel with $1 \mathrm{x}$ TAE electrophoresis buffer and were stained with ethidium bromide.

\section{Results and discussion}

Genotypes from Latvia and mountain areas were selected for this study based on the hypothesis that white clover in high-altitude areas could be better adapted to intense UV radiation and changes in their genome will be different from the genetic variability of Latvian samples. The movement of retrotransposons after irradiation with UV-B radiation could be observed in all examined genotypes using the iPBS 2079 primer. In the genotype "Daile" retrotransposon displacements were detected already after 15 minutes of irradiation (Figure 2). Changes in the genotype of T. repens 'Daile' can be observed in three loci, manifested as both: locus deletion and insertion. Locus deletion (sample 13) compared to the control group was observed after both 15 minutes and 30 minutes of irradiation, however, after 45 minutes of irradiation, the specific locus did not differ from the control group. Insertions are observed at two loci (sample 11). They are observed in all groups - after 15, 30, and 45 minutes of UV-B irradiation compared to the control group. For some individuals, exposure to UV-B radiation for 15 minutes a day during the week resulted in DNA degradation, so they were excluded from further analysis. In genotype 7, after 30 minutes of irradiation with UV-B radiation for the first sample, locus insertion can be found, but after 45 minutes of irradiation, the sample was degraded. In the second and sixth samples, locus deletion can be detected for 45 minutes after irradiation with UV-B radiation.

The majority (nine out of fifteen) of genotype individuals were degraded. After 15 minutes of irradiation with UV-B radiation, deletion of the locus can be observed in the first sample, however, 30 minutes after irradiation, the locus does not differ from the control group. The same sample DNA after 45 minutes with UV-B radiation was degraded. Irradiation for 45 minutes with UV-B radiation is too intense for this genotype, so degradation of most samples is observed. 

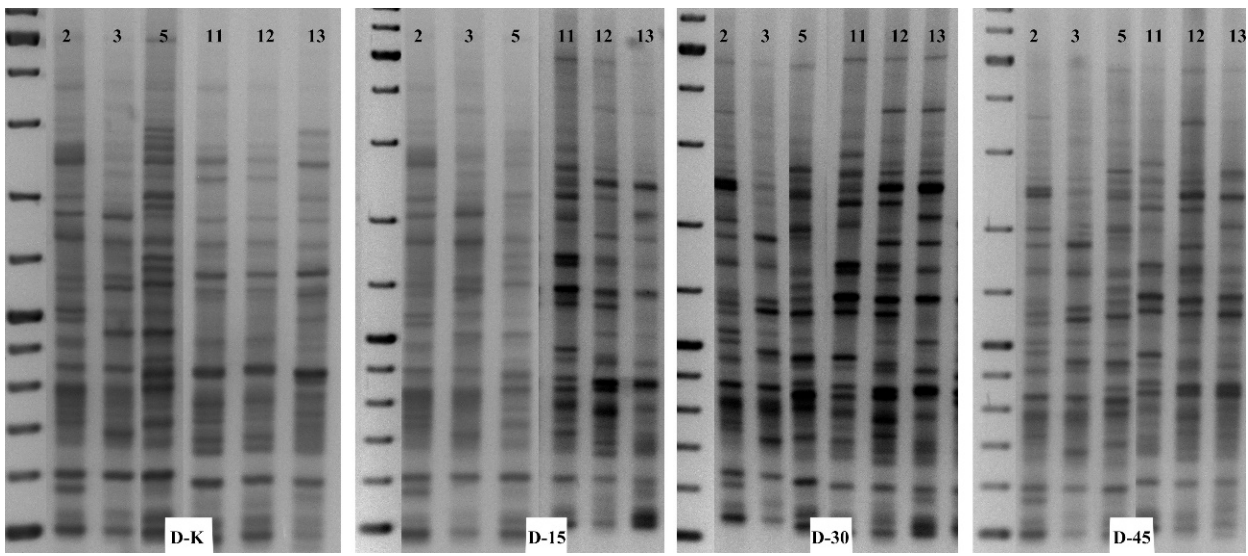

Figure 2. Movement of retrotransposons in the "Daile" genotype using the iPBS 2079 primer (D-K - control; D-15 - irradiation with UV-B radiation for 15 minutes; D-30 irradiation with UV-B radiation for 30 minutes; D-45 - irradiation with UV- B radiation for 45 minutes).

For genotype 11 samples after 15 minutes of UV-B irradiation, all samples DNA were degraded and these samples were removed from further analysis. In the fifth locus, 30 minutes after irradiation, locus insertion can be observed, which can also be observed after 45 minutes of irradiation, but in the sixth and seventh samples, locus deletion can be observed after both 30 and 45 minutes of UV-B irradiation.

Based on the features of the length marker in both genotype 11 and Daile retrotransposons, displacements have been detected around the same DNA region.

Genetic diversity is essential for any species to be able to adapt to and survive changing environmental conditions. This is particularly important because the climate on our planet is currently deteriorating due to human activity. To improve the quality of food and the environment, it is necessary to preserve and stabilize the genetic diversity of species. There is a need not only to improve the genetic diversity of crops but also to pay attention to their wild ancestors. Plant genetic resources are the basis for ecological and high-quality environmental development, ensuring the conservation of food and other biological resources. As a result of anthropogenic influences, natural ecosystems are fragmented, leading to a decline in genetic diversity, as the natural distribution of many species is limited (Maxted et al., 2008). Small, isolated populations are potentially at risk of inbreeding, loss of genetic diversity and are at risk of genetic erosion. Genetic diversity helps the species to evolve and to protect itself from inbreeding, which has a negative effect, as the possibility of this can increase the number of harmful recessive alleles in natural cross-pollinated populations. Studies show that increased genetic erosion 
affects $20-35 \%$ of plant species diversity. Crops account for only about $3 \%$ of all plant species. Plant genetic diversity increases choice and protection against future adverse environmental conditions (Bome et al., 2015; Frankham et al., 2017).

According to the results, it can be observed that after the treatment with UV-B radiation, the movement of retrotransposons is activated, which suggests that in this way protection against UV-B radiation is provided. It can be observed that the insertion of retrotransposons after irradiation with UV-B radiation within the same genotype takes place in the approximately same location in all the examined groups - after UV-B irradiation 15, 30, and 45 minutes, however, the literature reports, that retrotransposon insertion occurs randomly (Masuta et al., 2017), usually in non-chromatic regions. Based on the features of the length marker in two genotypes ( $11^{\text {th }}$ and "Daile"), retrotransposon displacements were detected around the same DNA region. The results could be extended by sequencing specific loci, as well as studying the gene functions of specific insertion sites using information available in databases.

\section{Acknowledgments}

This work was performed in the implementation of LU project Y5-AZ81ZF-N-805 "Living organisms research in towns, country, and water ecosystems".

\section{References}

Bome, N. A., Bome, A. Y., and Ripberger, E. I. 2015. Ecological and genetic potential of sort spring wheat in conditions of the northern zauralye. In: Biological Systems, Biodiversity, and Stability of Plant Communities. Eds. Weisfeld, Opalko, Bome, and Bekuzarova. 527 p.

Bui, Q. T., Grandbastien, M. A. 2012. LTR Retrotransposons as Controlling Elements of Genome Response to Stress? In: Plant Transposable Elements: Impact on Genome Structure and Function Topics in Current Genetics. Eds. Grandbastien and Casacuberta. Pp. 273-296.

Caradus, J. R. 1994. Genetic diversity within white clover (Trifolium repens L.). Proceedings Agronomy Society of N. Z. 24: 1-7.

Casacuberta, E., Gonzalez, J. 2013. The impact of transposable elements in environmental adaptation. Molecular Ecology. 22: 1503-1517.

Doyle, J. J., Doyle, J. L. 1987. A rapid DNA isolation procedure from small quantities of fresh leaf tissues. Phytochem Bull. 19(1): 11-15.

Frankham, R., Ballou, J. D., Ralls, K., Eldridge, M. D. B., Dudash, M. R., Fenster, C. B., Lacy, R. C., and Sunnucks, P. 2017. Genetic Management of Fragmented Animal and Plant Populations. Oxford University Press, 401. p.

Jansone, B. 2008. Baltais āboliņš (White clover). In: Celvedis daudzgadīgo zālaugu sēklaudzēšanā (Guide Book in the Seed Production of Forage Grasses). Eds. Jansone, Rancāne, Dzenis, and Jansons. Pp. 78-87 (in Latvian). 
Kalendar, R., Antonius, K., Smykal, P., and Schulman, A. H. 2010. iPBS: a universal method for DNA fingerprinting and retrotransposon isolation. Theor. Appl. Genet. 121: 1419-1430.

Masuta, Y., Nozawa, K., Takagi, H., Yaegashi, H., Tanaka, K., Ito, T., Saito, H., Kobayashi, H., Matsunaga, W., Masuda, S., Kato, A., and Ito, H. 2017. Inducible Transposition of a HeatActivated Retrotransposon in Tissue Culture. Plant Cell Physiol. 58(2): 375-384.

Maxted, N., Iriondo, J. M., Dulloo, M. E., and Lane, A. 2008. Introduction: The Integration of PGR Conservation with Protected Area Management. In: Conserving Plant Genetic Diversity in Protected Areas. Eds. Iriondo, Maxted, and Dulloo. Pp. 1-22.

Oliveira, A. F., Rais, F., Dettori, I., Azzena, M., and Nieddu, G. 2019. UV Light Acclimation Capacity of Leaf Photosynthetic and Photochemical Behaviour in Near-isohydric and Anisohydric Grapevines in Hot and Dry Environments. S. Afr. J. Enol. Vitic. 40(2): 188-205.

Ravagnani, A., Abberton Michael, T. and Skøt, L. 2012. Development of Genomic Resources in the Species of Trifolium L. and Its Application in Forage Legume Breeding. Agronomy. 2(2): $116-131$.

Romero-Román, M. E., Schoebitz, M., Bastías, R. M., Fernández, P. S., García-Viguera, C., and López-Belchi, M. D. 2021. Native Species Facing Climate Changes: Response of Calafate Berries to Low Temperature and UV Radiation. Foods. 10: 196.

Roze, I. 2003. Genus Trifolium L. in the flora of Latvia. Acta Biologica Universitatis Daugavpiliensis. 3(1): 33-40.

Roze, I. 2007. Āboliṇa Trifolium L. gints Latvijas florā (Clover Trifolium L. in the flora of Latvia). Latvijas Veǵetācija. 13: 17-32 (in Latvian, with English summary).

Taylor, N. L., Quesenberry, K. H. 1996. Red Clover Science. Eds. Summerfield. P. 228.

Voysey, C. R., White, D., Dudas, W. R., and Ealing, R. D. 1994. Agrobacterium mediated transformation of white clover. Plant Cell. 13: 309-314.

Zhang, Y., Sledge, M. K., and Bouton, J. H. 2007. Genome mapping of white clover (Trifolium repens L.) and comparative analysis within the Trifolieae using cross-species SSR markers. Theor Appl Genet. 114: 1367-1378. 